\title{
Cost of Illness of Malaria in Coastal Karnataka, India
}

\author{
Affan K', Sameer Phadnis ${ }^{2}, \underline{\text { Nahima Akthar }}$ \\ ${ }^{1}$ Postgraduate Student, ${ }^{2}$ Assistant Professor, ${ }^{3}$ Postgraduate Student of Master of Hospital Administration, Prasanna School of \\ Public Health, Manipal Academy of Higher Education. \\ DOI: https://doi.org/10.24321/0019.5138.202122
}

I $\quad \mathbf{N} \quad \mathbf{F} \quad \mathbf{O}$

Corresponding Author:

Affan K, Master of Public Health Program, Prasanna School of Public Health, Manipal Academy of Higher Education, Manipal, Karnataka, India.

E-mail Id:

affana9@gmail.com

Orcid Id:

https://orcid.org/0000-0002-3891-8218

How to cite this article:

Affan K, Phadnis S, Akthar N. Cost of Illness of Malaria in Coastal Karnataka, India. J Commun Dis. 2021; 53(2): 28-34.

Date of Submission: 2021-02-23

Date of Acceptance: 2021-06-04
$\begin{array}{llllllll}\mathbf{A} & \mathbf{B} & \mathbf{S} & \mathbf{T} & \mathbf{R} & \mathbf{A} & \mathbf{C} & \mathbf{T}\end{array}$

Background: Malaria is one of the major health issues in developing and underdeveloped countries. It is considered to be one of the main reasons for morbidity and mortality. This study intends to estimate the cost of illness of malaria at the household level and health service utilisation pattern for malaria treatment in coastal Karnataka.

Materials and Methods: It was a secondary data-based cross-sectional study comprising people suffering from malaria during the period from September to December 2016.

Result: The median gross total cost of illness (a single episode of malaria) was 4,000 INR, the median direct medical cost was zero, and the median direct non-medical cost was 100 INR. The majority of individuals $(92.2 \%)$ took treatment from public healthcare sectors.

Conclusion: The effective implementation of anti-malarial interventions by the District Health Authority, District Vector Borne Disease Control Office, and treatment from public health sectors resulted in negligible direct medical cost which made a remarkable reduction in the cost of illness of malaria.

Keywords: Malaria, Cost of illness, Vector-borne, Treatment, Public health Sector, Health Insurance

\section{Introduction}

Malaria is a severe public health issue all around the world, especially in tropical, subtropical regions, and underdeveloped parts of the world. Malaria is one of the main reasons for deaths and morbidity in underdeveloped and developing countries. ${ }^{1}$ It was found that around 3.2 billion people are living at a high possibility of being infected with malaria in 106 countries and union territories. Among the total global malarial cases, $13 \%$ were found in the countries of the Southeast Asia Region (SEAR). In India, nearly 539 million population are residing in high transmission zones which are defined as the area having more than one malaria incidence per 1000 population. It has been estimated that almost $61 \%$ of malaria cases and $41 \%$ of malaria deaths among SEAR countries happens in India alone. ${ }^{2}$

India is having a national health programme for malaria control since 1953 which has been working as an umbrella programme named "National Vector Borne Disease Control Programme (NVBDCP)" since 2004. The actual incidence of malaria is higher and a substantial number of infected people may look for treatment from private healthcare sectors that don't answer to NVBDCP. ${ }^{3}$ Researchers have identified that actual malaria cases in India are 9 to 50 
times higher than the government health authority data. ${ }^{4}$

It has been found that the reason behind underreporting is the broad Annual Blood Examination Rate (ABER). It indicates insufficient malaria surveillance by Indian states, poor quality of smear examination, and negligence in reporting the cases by the private health sector. The aggregate economic burden due to malaria fever was around 1940 million US dollars. It is assumed that each Rupee put into control of malaria fever in India produces an immediate return of 19.70 INR. ${ }^{5}$ Globally each instance of malaria has been appeared to cost family units in any event. Mothers and different caretakers give up an additional 2 to 4 days whenever a kid or relative suffers from malaria, which creates even more indirect expenses for households. ${ }^{6}$

Prior literature stated that the average total cost of treatment in India was around 475 INR for a person in 2012, whereas the loss of earnings in a day was around 213 INR. Also, the total days of work loss were found to be around 10 days. Death rates due to malaria are not a noteworthy element because $75 \%$ of the burden originates from income loss and $25 \%$ occurs from expenditures of treatment. ${ }^{7}$ A study in 2015 revealed that in India nearly 21.6 crore individuals are covered under health insurance, which is less than $1 / 5$ th of India's total population. However, around $67 \%$ of individuals among those 21.6 crores are covered by public sector health insurance companies. ${ }^{8}$ It is found that in India, the private healthcare sector is essential and it is the primary foundation in the country's healthcare system. In urban India, around $70 \%$, and in the rural picture of the country, nearly $63 \%$ of families are depending on the private healthcare sector for their healthcare issues. ${ }^{9}$

Researchers have observed poor health-seeking behaviour and health insurance coverage in the case of malaria. ${ }^{10}$ If the highest malaria burden among people with low socio-economic status is taken into consideration then the malaria morbidity is expected to be doubled and also the loss of productivity due to malaria would become a considerable part of the total economic burden. Presently in India, malaria may not result in many deaths, but it puts an enormous burden through sickness and also loss of productivity which affects households' welfare. At a macro level, it affects the country's growth and income whereas at a micro-level, individual and family expenditures will be affected. ${ }^{11,12}$ Although the above-mentioned situations are in India, there are no studies that estimate the microeconomic cost of illness of households who suffered from malaria.

\section{Objectives of the Study}

To estimate the direct and indirect costs incurred by the malaria patients in an urban area of a district of coastal Karnataka.

To ascertain the pattern of health service utilisation among people suffering from malaria in an urban area of a district of coastal Karnataka.

\section{Materials and Methods \\ Study Design}

Retrospective cross-sectional study.

\section{Study Setting}

The study was conducted in an urban area of a district of coastal Karnataka.

\section{Study Duration}

This study was carried out for 5 months starting from January 2017 to May 2017.

\section{Inclusion Criteria}

The study involves people suffering from malaria (laboratory positive smear cases) in an urban area of a district of coastal Karnataka, reported to the District Vector Borne Disease Control Office (DVBDCO) of that district during the period from September to December 2016.

\section{Exclusion Criteria}

People denying to give consent for the participation and those who were diagnosed with Rapid Diagnostic Kit alone were excluded from the study.

\section{Study Tool}

A structured questionnaire was used to collect data from the participants.

The following details were collected using the questionnaire:

- Socio-demographic details

- The health scheme/ insurance status of the respondent, type of health insurance, and insurance that is instrumental in reducing the cost

- Healthcare utilisation pattern during malaria

- Cost Information: Estimation of cost of illness has been made based on the two components:

Direct Cost: It includes direct medical cost and direct nonmedical cost for both outpatient and in-patient care.

Indirect Cost: It includes indirect expenses of both ill patients and their caregivers.

\section{Data Collection}

There were 183 laboratory smear-positive cases of malaria during the period from September to December 2016. Amongst them, 128 individuals gave consent for participation in the study. The researcher approached the study participants with the questionnaire. Before giving the questionnaire to the participant, the researcher explained the purpose and procedure of the study and then obtained the written consent. 


\section{Data Analysis}

The data were entered and analysed in the statistical software SPSS version 16. Descriptive statistics were expressed as frequencies and percentages. Summary statistics of direct and indirect costs were reported as a median and inter-quartile range.

\section{Ethical Considerations}

Ethical clearance for the study was obtained from the Institutional Ethics Committee (IEC No. 918/2016). Involvement in the study was voluntary. Informed consent was obtained from the participants and the reason behind the study was revealed to them using a predefined information sheet. All the study participants were guaranteed privacy and anonymity and efforts were made to make sure the concealment of the material.

\section{Result}

\section{Socio-demographic Characteristics of the Study Participants}

128 participants were included in the study. The details of the demographic profile are presented in Table 1.

\section{Cost of Illness}

The data collected for the calculation of the cost of illness was not normally distributed. This was because of the wide disparity in the data due to the presence of zero and extreme values. Therefore, median and Inter-Quartile Range (IQR) were used to compare the variables in two or more subgroups.

\section{Direct Cost}

The median of the total direct cost of illness incurred by study subjects was found to be 120 INR for a single episode of malaria (IQR-291.25). The total direct cost of illness constituted to be $12.27 \%$ of the total cost of illness. The median of the direct medical cost of illness was observed to be zero (IQR-190), whereas the median of direct nonmedical cost of illness was detected to be 100 INR (IQR-140) for a single episode of malaria.

The breakdown of the direct cost for the treatment of malaria at the outpatient level is formulated in Table 2.

\section{Indirect Cost}

The breakdown of indirect cost for the treatment of malaria at the outpatient level is expressed in Table 3.

\section{Direct Cost of Hospitalisation and Outpatient Visits}

The breakdown of the direct cost for the treatment of malaria during outpatient visits and hospital stays is shown in Table 4.
Table I.Socio-demographic Characteristics of the Study Participants

\begin{tabular}{|c|c|c|}
\hline Characteristics & Number & Percentage \\
\hline \multicolumn{3}{|c|}{ Gender } \\
\hline Female & 23 & 18.0 \\
\hline Male & 105 & 82.0 \\
\hline \multicolumn{3}{|c|}{ Age (in years) } \\
\hline $0-15$ & 11 & 8.6 \\
\hline $16-30$ & 58 & 45.3 \\
\hline $31-50$ & 52 & 40.6 \\
\hline Above 51 & 7 & 5.5 \\
\hline \multicolumn{3}{|c|}{ Religion } \\
\hline Hindu & 120 & 93.8 \\
\hline Muslim & 7 & 5.5 \\
\hline Christian & 1 & 0.8 \\
\hline \multicolumn{3}{|c|}{ Per-capita monthly income (in rupees) } \\
\hline 949 to 1,835 & 5 & 3.9 \\
\hline 1,836 to 3,098 & 66 & 51.6 \\
\hline 3,099 to 6,260 & 56 & 43.8 \\
\hline 6,261 and above & 1 & 0.8 \\
\hline \multicolumn{3}{|c|}{ Educational status of the participant } \\
\hline Illiterate & 7 & 5.5 \\
\hline Primary school certificate & 41 & 32.0 \\
\hline Middle school certificate & 29 & 22.7 \\
\hline High school certificate & 39 & 30.5 \\
\hline $\begin{array}{l}\text { Intermediate or post-high } \\
\text { school diploma }\end{array}$ & 11 & 8.6 \\
\hline Graduate or postgraduate & 1 & 0.8 \\
\hline \multicolumn{3}{|c|}{ Occupational status of the respondent } \\
\hline Unemployed/Student & 18 & 14.1 \\
\hline Unskilled worker & 50 & 39.1 \\
\hline Semi-skilled worker & 53 & 41.4 \\
\hline Skilled worker & 5 & 3.9 \\
\hline $\begin{array}{c}\text { Clerical, shop owner, } \\
\text { farmer }\end{array}$ & 2 & 1.6 \\
\hline
\end{tabular}

\section{Indirect Cost of Hospitalisation and Outpatient Visits}

The breakdown of indirect costs for the treatment of malaria during hospitalisation and hospital visits is conveyed in Table 5. 
Table 2.Breakdown of the Direct Cost of Illness

\begin{tabular}{|c|c|c|c|c|}
\hline \multicolumn{2}{|c|}{ Direct Cost } & $\begin{array}{c}\text { Cost (in } \\
\text { rupees) }\end{array}$ & $\begin{array}{c}\text { Interquartile } \\
\text { Range }\end{array}$ & $\begin{array}{c}\text { Median (in } \\
\text { rupees) }\end{array}$ \\
\hline \multirow{4}{*}{\begin{tabular}{c} 
Direct medical $\begin{array}{c}\text { cost } \\
\text { cost }\end{array}$ \\
\cline { 2 - 5 }
\end{tabular}} & Total consultation charges & 1320.00 & 0.00 & 0.0000 \\
\cline { 2 - 5 } & Total laboratory charges & 3530.00 & 0.00 & 0.0000 \\
\hline \multirow{2}{*}{$\begin{array}{c}\text { Direct non- } \\
\text { medical cost }\end{array}$} & Total medicinal cost & 0.00 & 0.00 & 0.0000 \\
\cline { 2 - 5 } & Special diet and food charge & 0.00 & 0.00 & 0.0000 \\
\hline
\end{tabular}

Table 3.Breakdown of the Indirect Cost of Illness

\begin{tabular}{|c|c|c|c|}
\hline Indirect Cost & Sum & Interquartile Range & Median \\
\hline $\begin{array}{l}\text { Lost paid working hours of the respondent due to malaria } \\
\text { illness (in hours) }\end{array}$ & 7658.00 & 50.50 & 68.0000 \\
\hline Lost wages of the respondent due to malaria illness (in rupees) & 356198.00 & 2497.50 & 3330.0000 \\
\hline $\begin{array}{l}\text { Lost unpaid working hours of the respondent due to malaria } \\
\text { illness (in hours) }\end{array}$ & 239.00 & 9.00 & 12.0000 \\
\hline $\begin{array}{l}\text { Lost paid working hours of the companion due to malaria } \\
\text { illness of respondent (in hours) }\end{array}$ & 1689.00 & 49.50 & 20.0000 \\
\hline $\begin{array}{l}\text { Lost wages of the companion due to malaria illness of } \\
\text { respondent (in rupees) }\end{array}$ & 83570.00 & 2280.00 & 950.0000 \\
\hline $\begin{array}{l}\text { Lost unpaid working hours of the companion due to malaria } \\
\text { illness of respondent (in hours) }\end{array}$ & 0.00 & - & 0.0000 \\
\hline $\begin{array}{l}\text { Total charges incurred due to appointing paid caregiver } \\
\text { including travelling, food and service charges }\end{array}$ & 0.00 & - & 0.0000 \\
\hline
\end{tabular}

Table 4.Breakdown of the Direct Cost of Illness including Outpatient Visits and Hospitalisation Cost

\begin{tabular}{|c|c|c|c|c|}
\hline \multicolumn{1}{|c|}{ Direct Cost } & $\begin{array}{c}\text { Cost (in } \\
\text { rupees) }\end{array}$ & $\begin{array}{c}\text { Interquartile } \\
\text { Range }\end{array}$ & $\begin{array}{c}\text { Median (in } \\
\text { rupees) }\end{array}$ \\
\hline \multirow{4}{*}{$\begin{array}{c}\text { Direct } \\
\text { medical cost }\end{array}$} & Total OP consultation charges & 1100.00 & 50.00 & 0.0000 \\
\cline { 2 - 5 } & Total OP laboratory charges & 1800.00 & 0.00 & 0.0000 \\
\cline { 2 - 5 } & Total other OP diagnostic procedure charges & 0.00 & - & 0.0000 \\
\cline { 2 - 5 } & Total OP medicinal cost & 570.00 & 20.00 & 0.0000 \\
\cline { 2 - 5 } & Total hospital stay charges & 15285.00 & 1200.00 & 20.0000 \\
\cline { 2 - 5 } & Total IP consultation charges & 13350.00 & 800.00 & 0.0000 \\
\cline { 2 - 5 } & Total IP laboratory charges & 7250.00 & 250.00 & 130.0000 \\
\cline { 2 - 5 } & Total other IP diagnostic procedure charges & 0.00 & - & 0.0000 \\
\cline { 2 - 5 } & Total IP medicinal charges & 3619.50 & 222.00 & 0.0000 \\
\hline \multirow{4}{*}{$\begin{array}{c}\text { Direct non- } \\
\text { medical cost }\end{array}$} & Other hospital procedure charges & 990.00 & 0.00 & 0.0000 \\
\cline { 2 - 5 } & Special diet and food charge in OP visits & 0.00 & - & 0.0000 \\
\cline { 2 - 5 } & Total travelling cost in OP visits & 1336.00 & 100.00 & 0.0000 \\
\cline { 2 - 5 } & Special diet and food charge in IP visits & 0.00 & - & 0.0000 \\
\hline
\end{tabular}


Table 5.Breakdown of the Indirect Cost of Illness including Outpatient and Hospitalisation Cost

\begin{tabular}{|c|c|c|c|}
\hline Indirect Cost & Sum & Interquartile Range & Median \\
\hline $\begin{array}{l}\text { Lost paid working hours of the respondent due to malaria } \\
\text { illness (in hours) }\end{array}$ & 2345.00 & 52.00 & 75.0000 \\
\hline $\begin{array}{l}\text { Lost wages of the respondent due to malaria illness } \\
\qquad \text { (in rupees) }\end{array}$ & 120070.00 & 2340.00 & 3330.0000 \\
\hline $\begin{array}{l}\text { Lost unpaid working hours of the respondent due to malaria } \\
\text { illness (in hours) }\end{array}$ & 80.00 & 20.50 & 15.0000 \\
\hline $\begin{array}{l}\text { Lost paid working hours of the companion due to malaria illness } \\
\text { of respondent (in hours) }\end{array}$ & 795.00 & 42.25 & 27.0000 \\
\hline $\begin{array}{l}\text { Lost wages of the companion due to malaria illness of } \\
\text { respondent (in rupees) }\end{array}$ & 35920.00 & 2845.00 & 1110.0000 \\
\hline $\begin{array}{l}\text { Lost unpaid working hours of the companion due to malaria } \\
\text { illness of respondent (in hours) }\end{array}$ & 463.00 & 9.00 & 20.0000 \\
\hline $\begin{array}{c}\text { Total charges incurred due to appointing paid caregiver } \\
\text { including travelling, food, } \\
\text { and service charges }\end{array}$ & 0.00 & - & 0.0000 \\
\hline
\end{tabular}

The study states that amongst 128 study participants, 126 participants were at the risk of out-of-pocket expenditure (OOPE) due to malaria as they were not having any health insurance coverage. But among them, 118 study subjects took anti-malarial treatment in different public healthcare facilities. Hence, they could avoid OOPE. Here one of the reasons for these individuals not visiting private healthcare sectors may be their lack of insurance, without which they could come across a huge catastrophic direct cost of expenditure for their treatment.

The study discloses that 97 respondents were treated at the outpatient level in public healthcare facilities with negligible direct medical costs. The study reveals that no respondents were treated for malaria at the outpatient level in private healthcare centres. It was observed that among the remaining 31 respondents, 21 respondents were admitted to public health sectors. All of these 21 subjects were not having any health insurance coverage. The total direct medical costs borne by them were found to be very insignificant. The median of total direct medical costs borne by them was found to be zero (IQR 186.25). Some of them paid user fees for hospital staying charge and the cost for a few blood investigations which was showing a sum of 175 INR and 1,480 INR respectively. These respondents were admitted to health facilities for a median of 3 days (IQR 0.75).

However, among the remaining 10 study participants, four each were belonging to the middle-class and uppermiddle-class socioeconomic status, whereas one each was belonging to the lower-middle-class and upper-class status. Among them, two participants were admitted to private health sectors with health insurance coverage. But they had to pay out-of-pocket of a median of 1,000 INR as hospital charges even after utilising their health insurance policy, as their health insurance policy could not cover their total illness expenditure. Hence the median of total direct medical charges was found to be 1,000 INR. These respondents were admitted to health facilities for a median of 6 days (IQR is not available as $n$ is very small i.e. 2).

Eight study participants who were admitted to private health sectors without health insurance coverage had incurred huge direct medical charges. They incurred a median of total direct medical charges of 3,509 INR (IQR 3070.25) for a single episode of malaria. These study respondents were admitted to health facilities for a median of 8 days (IQR 3.5). It was found that all study subjects who took treatment for malaria at public health facilities were not having any health insurance coverage.

\section{Health Service Utilisation}

Public healthcare centres were utilised most commonly (60.2\%) after the onset of fever and before diagnosis.

\section{Before Diagnosis}

The type of health facility visited by the respondents during the onset of fever is stated in Table 6.

\section{After Diagnosis}

The type of health facility visited by the respondents after diagnosis of malaria is specified in Table 7. 
Table 6. Types of Healthcare Facilities visited before Diagnosis

\begin{tabular}{|c|c|c|}
\hline Health Facility & Frequency & Percentage \\
\hline Government hospital & 26 & 20.3 \\
\hline $\begin{array}{l}\text { Primary/ urban health } \\
\text { centre }\end{array}$ & 27 & 21.1 \\
\hline $\begin{array}{l}\text { Other public sector health } \\
\text { facility }\end{array}$ & 24 & 18.8 \\
\hline NGO or Trust hospital/ clinic & 1 & 0.8 \\
\hline $\begin{array}{l}\text { Private hospital/ nursing } \\
\text { home }\end{array}$ & 9 & 7.0 \\
\hline Private clinic & 20 & 15.6 \\
\hline Pharmacy/drug store & 16 & 12.5 \\
\hline $\begin{array}{c}\text { Self-prescription/ home } \\
\text { treatment }\end{array}$ & 5 & 3.9 \\
\hline Total & 128 & 100.0 \\
\hline
\end{tabular}

Table 7.Types of Healthcare Facilities visited after Diagnosis

\begin{tabular}{|c|c|c|}
\hline Health Facility & Frequency & Percentage \\
\hline Government hospital & 64 & 50.0 \\
\hline $\begin{array}{c}\text { Primary/ urban health } \\
\text { centre }\end{array}$ & 25 & 19.5 \\
\hline $\begin{array}{c}\text { Other public sector health } \\
\text { facility }\end{array}$ & 29 & 22.7 \\
\hline $\begin{array}{c}\text { Private hospital/ nursing } \\
\text { home }\end{array}$ & 10 & 7.8 \\
\hline Total & 128 & 100.0 \\
\hline
\end{tabular}

\section{Discussion}

The study has observed that the majority of the study participants were male (82\%). This is similar to the study conducted in the past. ${ }^{13,14}$ But in some studies, it was found that females were at an increased risk of malaria as they were engaged in domiciliary activities..$^{15}$ The study participants aged from 16 to 30 years and 31 to 50 years were more in numbers which affected larger financial loss in these age groups. A similar study has revealed that productivity loss was found as the utmost percentage for the indirect expenses of both malaria patients and caregivers. Young and middle-aged individuals had more incidence of malaria fever which led to a huge monetary loss. ${ }^{13}$

Most of the study participants (92.2\%) took treatment from different public healthcare facilities, where the malaria diagnosis and anti-malarial treatment is free of cost except for a few blood investigations and hospital stay which can become free of cost if the patient discloses his/ her proof of Below Poverty Line card. Hence it is evident by this study that the direct medical cost of illness for the treatment of malaria at the in-patient level was negligible in public healthcare centres whereas it causes huge out-of-pocket expenditure in private healthcare centres if the individual is pursuing treatment without any health insurance coverage. The study states that amongst 128 study participants, 126 participants were at the risk of out-of-pocket expenditure (OOPE) due to malaria as they were not having any health insurance coverage. It was observed in this study that people preferred to visit public health sectors. The results of the previous studies show that most of the people residing in India visit public health facilities for the treatment of febrile illness. ${ }^{16,17}$

The current study found that hospitalisation expenditures are higher than outpatient expenditures. The indirect cost contributes $87.72 \%$ of the total expenditure of malaria illness, while the direct cost adds to the remaining $12.27 \%$. Hence, the current study states that indirect cost is much more than the direct cost of illness. A similar study conducted in India states that malaria requires more outpatient expenditure (175 rupees average) than hospitalisation expenditure ( 75 rupees average). It was also observed that the topmost burden came from the loss of income as $75 \%$ and the residual $24 \%$ came from expenses related to medications. ${ }^{9}$

In the present study, it was found that households that suffered from malaria had sustained $12.27 \%$ of direct expenses, $70.12 \%$ of indirect expenses, and their caregivers had to bear $17.59 \%$ of indirect cost. A similar study states that for each person who suffered from malaria and who was fully cured of it, a household on average sustained an entire expense of 7 US dollars, in which direct expense was $24 \%$, and indirect expense was $44 \%$ for the patient, whereas the indirect expense was $32 \%$ for the household. For those who pursued treatment in the private sector, the direct expenditures were high. One of the huge sections of direct expenditures was paid on things like nutritional foods and vitamins. ${ }^{9,18}$

In the current study, public healthcare centres were used most commonly (60.2\%) after the onset of fever, before the diagnosis. Among 128 respondents, $88.27 \%$ of the individuals were diagnosed with malaria fever in public sector health facilities. Overall, $92.2 \%$ of the study participants made their visit to the public health sectors after being diagnosed with malaria. Similar findings were observed in a previous study. ${ }^{19}$ However, in some studies, it was found that there was a lack of the practical execution of allopathic treatment practice. The individuals who had a febrile illness were not approaching the health facilities during the onset of fever. They were either practising selfmedication or they were approaching the non-healthcare sources before approaching the actual health facilities. ${ }^{10,20}$ 


\section{Conclusion}

This study found that the individuals had to incur a heavy burden of indirect cost due to malaria. The proportion of individuals with health insurance coverage was $1.6 \%$ and about $72.7 \%$ of individuals had to face out-of-pocket expenditure. But due to the effective implementation of anti-malarial interventions by the District Health Authority and District Vector Borne Disease Control Office, the majority of individuals (92.2\%) took treatment from public health sectors which resulted in negligible direct medical cost and caused a remarkable reduction in the direct cost of illness.

\section{Acknowledgement}

The authors appreciate the District Vector Borne Disease Control Officer for active participation in the study. The authors also convey special thanks to the staff of DVBDCO who helped the researcher to obtain details of the study participants. The authors also express their gratitude to all the study participants.

Source of Funding: It is a self-funded project

\section{Conflict of Interest: None}

\section{References}

1. World Health Organization. World Malaria Report 2016. Available from: https://apps.who.int/iris/bitstream/ handle/10665/252038/9789241511711. [Internet]

2. World Health Organization. World Malaria Report 2014. Available from: https://apps.who.int/iris/ handle/10665/144852 [Internet]

3. Directorate of National Vector Borne Disease Control Programme. Strategic Plan for Malaria Control in India 2012-2017 A Five-year Strategic Plan. MOHFW; 2008. Available from: https://nvbdcp.gov.in/Doc/StrategicAction-Plan-Malaria-2012-17. [Internet]

4. Hay SI, Gething PW, Snow RW. India's invisible malaria burden. Lancet. 2010;376(9754):1716-7. [Google Scholar]

5. Sachs J, Malaney P. The economic and social burden of malaria. Nature. 2002;415(6872):680-5. [PubMed] [Google Scholar]

6. Kumar A, Valecha N, Jain T, Dash AP. Burden of malaria in India: Retrospective and prospective view. Am J Trop Med Hyg. 2007;77:69-78. [PubMed] [Google Scholar]

7. Breman JG, Alilio MS, White NJ. Defining and defeating the intolerable burden of malaria III. Progress and perspectives. Am J Trop Med Hyg. 2007;77. [Google Scholar]

8. WHO. Global technical strategy for malaria 2016-2030. World Health Organization. 2015. [Google Scholar]

9. Gupta I, Chowdhury S. Economic burden of malaria in India: The need for effective spending. WHO South-
East Asia J Public Health. 2014;3(1):95-102. [PubMed] [Google Scholar]

10. Ahmed SM, Haque R, Haque U, Hossain A. Knowledge on the transmission, prevention and treatment of malaria among two endemic populations of Bangladesh and their health-seeking behaviour. Malar J. 2009;8:173. [PubMed] [Google Scholar]

11. Attanayake N, Fox-Rushby J, Mills A. Household costs of "malaria" morbidity: A study in Matale district, Sri Lanka. Trop Med Int Health. 2000;5(9):595-606. [PubMed] [Google Scholar]

12. Asante FA, Asenso-Okyere K. Economic Burden of Malaria in Ghana. WHO African Region Office. 2003. [Google Scholar]

13. Yadav SP. A study of treatment seeking behaviour for malaria and its management in febrile children in rural part of desert, Rajasthan, India. J Vector Borne Dis. 2010;47(4):235-42. [PubMed] [Google Scholar]

14. Unnikrishnan B, Jaiswal A, Reshmi B. Awareness and treatment seeking behaviour of people affected with malaria in coastal south India. Iran J Public Health. 2008;37(1). [Google Scholar]

15. Ayele DG, Zewotir TT, Mwambi HG. Prevalence and risk factors of malaria in Ethiopia. Malar J. 2012;11:195. [PubMed] [Google Scholar]

16. Patel D, Patel K, Patel K, Patel P, Patel S, Bansal R. Assessment of out of pocket expenditure for treatment of malaria in Surat city. Natl J Community Med. 2016;7(9):741-4. [Google Scholar]

17. Sekher TV. Catastrophic health expenditure and poor in India: health insurance is the answer. Proceedings of the 27th IUSSP International Population Conference 2013 Aug (2013) [Google Scholar]

18. Central Bureau of Health Intelligence (India). India National Health Profile 2009. New Delhi, India. Available from: http://ghdx.healthdata.org/record/ india-national-health-profile-2009. [Internet]

19. Chaturvedi HK, Mahanta J, Pandey A. Treatment-seeking for febrile illness in north-east India: An epidemiological study in the malaria endemic zone. Malar J. 2009;8:301. [PubMed] [Google Scholar]

20. Dida N, Darega B, Abebe A. Treatment Seeking Behavior and Associated Factors among Malaria Suspected Patients in Bale Zone, Southeast Ethiopia: InstitutionBased Cross-sectional Study. J Fam Med. 2015;2(1):5. [Google Scholar] 